Jan Kalbheim

\title{
Über Reden und Überdenken
}

Der Kampf um die Rechtsprechungsänderung durch den Europäischen Gerichtshof als Kristallisationspunkt des europäischen juristischen Diskurses

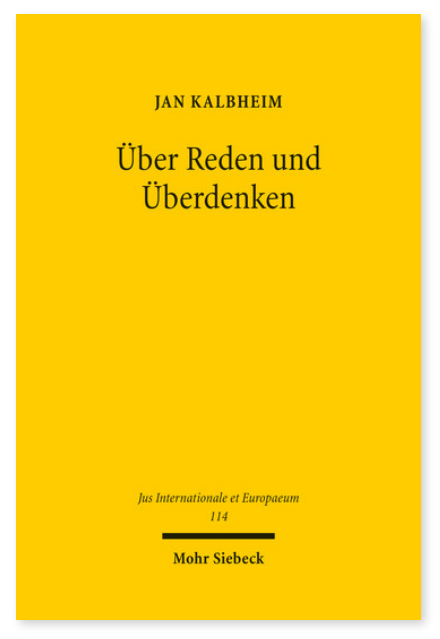

2016. XX, 558 Seiten. JusIntEu 114

ISBN 978-3-16-154223-7

DOI 10.1628/978-3-16-154223-7

eBook PDF 104,00€

ISBN 978-3-16-154222-0

fadengeheftete Broschur 104,00€
Recht lebt in und von der Sprache. Daher ist der juristische Diskurs elementar für die Entwicklung rechtlicher Ordnung, auch der Europarechtsordnung. Jan Kalbheim analysiert zunächst die Diskurssituation des Europäischen Gerichtshofs als eines gewichtigen Diskursteilnehmers innerhalb der offenen Gesellschaft der Europarechtsinterpreten sowohl in personeller, als auch in institutioneller Hinsicht. Sodann untersucht er, ausgehend vom Kampf um die Änderung der EuGH-Rechtsprechung, diesen Diskurs in sechs exemplarischen Fallstudien. Damit erschließt er einen neuen Zugang zum Verständnis der Rechtsprechung des Europäischen Gerichtshofs und verdeutlicht die Aufgabe der anderen Diskursteilnehmer, insbesondere der nationalen Höchstgerichte und der Rechtswissenschaft, den europäischen juristischen Diskurs durch konstruktive Kritik dieser Rechtsprechung offen zu halten.

Jan Kalbheim Geboren 1965; Studium der Rechtswissenschaften, Geschichte und Sinologie in Trier und Bonn; Staatsexamina in Düsseldorf und Hamburg; DAAD-Fachlektor für Deutsches Recht an der University of Strathclyde, Glasgow; wissenschaftlicher Mitarbeiter am Lehrstuhl für öffentliches Recht, Völker- und Europarecht der Universität Bayreuth; wissenschaftlicher Assistent am Lehrstuhl für Öffentliches Recht und Europarecht der LMU München; seit 2010 DAADFachlektor für Deutsches und Europäisches Recht an der Juristischen Fakultät der Karls-Universität zu Prag; 2015 Promotion.
Jetzt bestellen:

https://mohrsiebeck.com/buch/ueber-reden-und-ueberdenken-9783161542237?no_cache=1

order@mohrsiebeck.com

Telefon: +49 (0)7071-923-17

Telefax: $+49(0) 7071-51104$ 